\title{
Is an Appeal to Popularity a Fallacy of Popularity?
}

\section{DON DEDRICK}

\author{
Department of Philosophy \\ University of Guelph \\ Guelph, Ontario, Canada N1G 2WI \\ ddedrick@uoguelph.ca
}

\begin{abstract}
It is common to view appeals to popularity as fallacious. We argue this is a mistake and that Condorcet's jury theorem can be used to justify at least some appeals to popularity as legitimate inferences. More importantly, the conditions for the application of Condorcet's theorem (binary claim, competent judge, epistemic independence) can be used as critical tools when evaluating appeals to popularity. The application of these three concepts to appeals to popularity provide a more fine-grained critical strategy for argument evaluation and, also, allow us to see the real problems that often arise with such appeals more clearly.
\end{abstract}

Résumé: Il est courant de considérer les appels à la popularité comme fallacieux. Nous soutenons qu'il s'agit d'une erreur et qu'on peut utiliser le théorème du jury de Condorcet pour justifier au moins certains appels à la popularité en tant que déductions légitimes. Plus important encore, on peut employer les conditions d'application du théorème de Condorcet (assertion binaire, juge compétent, indépendance épistémique) comme des outils essentiels pour évaluer des appels à la popularité. L'application de ces trois concepts aux appels à la popularité fournit une stratégie critique plus fine pour l'évaluation des arguments et nous permet également de voir plus clairement les vrais problèmes qui se posent souvent avec de tels appels.

Keywords: critical thinking pedagogy, argumentation theory, informal fallacies, Condorcet's jury theorem, Kenneth Arrow, ad populum, appeal to popularity

"...Socrates suggests that majority opinion should not matter, since a good decision is based on knowledge rather than on numbers. And this wisdom is widely accepted today. Thus, almost every introductory textbook on critical thinking identifies popularity-based arguments as fallacies (ad populum): just because most people believe something does not mean that it is true" (Sytsma and Livengood 2016, p. 112). 


\section{Blatant and less blatant versions of appeal to popularity}

In Logical Self-Defence, their classic text on the fallacies as a guide to understanding how to reason well (and, especially, how to detect poor reasoning), Johnson and Blair describe a "blatant (and rare)" form of the fallacy of popularity like this (Johnson and Blair 2006, p. 176):

Positive form:

Everyone believes P; therefore

$\mathrm{P}$ is true.

Negative form:

No one believe $\mathrm{P}$; therefore

$\mathrm{P}$ is false.

This reasoning is, according to the authors, clearly "outrageous." Walton has said, in his own discussion of this form, that it is "unlikely to fool anyone" (Walton 1982, p. 268). A number of writers, including Johnson and Blair, note that there may be versions of this form that need to be set aside as actual fallacies of popularity. ${ }^{1}$ But in so far as we have identified the blatant form (because it is blatant, or because we can see that such a blatant form underlies some more complex expression) it is said to have nothing to recommend it. Since it is the blatant form we are interested in here, the reader can take it that we are referring to that form in our discussion (unless otherwise specified) using the expressions "fallacy of popularity" or "appeal to popularity" depending on whether we wish to identify the form as fallacious or describe it in a less question begging way. In line with this distinction we shall be arguing that, at least for some cases, the appeal to popularity (the blatant version) makes a legitimate inference.

In terms of logic, the appeal to popularity is clearly invalid. Yet the problem with such appeals is not merely logical. Suppose we adopt one common, non-deductivist, account of successful argumentation, an account according to which, minimally, an argument is good when [a] its premises are acceptable, and [b] its premises

${ }^{1}$ Other examples are Walton (1982); Freeman (1995); Govier (2005); Epstein (2011). 
provide sufficient support for its conclusion, and [c] the premises are relevant to the conclusion. This account allows us to extend evaluation of good/bad arguments beyond the scope of soundness, yet it retains an important feature of deductivist argument evaluation: an argument may be evaluated in terms of the acceptability of its premises but especially in terms of the sufficiency of its premises. Validity is one criterion for sufficiency, but there are others. None of this is controversial (except for those who demand a deductivist construal of "good/bad argument"). It does, however, allow us to recognize that what is interesting about some form of reasoning may be something other than validity/invalidity. Consider the fallacy-type named "hasty generalization." In such inferences, the sample size is too small, and we can often identify a fallacy because the sample size is 1 , or some other insignificant number. Such arguments are invalid, but a fallacy of hasty generalization is that fallacy because of sample size insufficiency, not because of mere invalidity. That is what is generalizable as the fallaciousness of a hasty generalization. What, then, are the generalizable aspects of appeals to popularity that are thought to make for a fallacy of popularity?

Johnson and Blair point out that it is not universal quantification that is at issue. The quantifiers, "all" or "none (no-one)" make the inference stark, but if we were to exclude cases where the appeal is to something like "most people" or "the majority" or "almost everyone" (conversely, to "almost no one" or "very few" or "nobody I know of"), then we would be excluding a feature that these and the universally quantified versions share: that it is popularity, not universal assent that matters. ${ }^{2}$ The essential fact is the unvarnished role of popularity in the inference...

\footnotetext{
${ }^{2}$ This is an empirical claim and cannot be established here. Consider, as a prelude to an empirical study, the following thought experiment: $A$ appeals to the universal assent to statement $x$ as a premise in an argument that is of the blatant form of appeal to popularity. $B$ notes the he/she does not assent to $x$. The premise in $A$ 's argument is therefore false. Does $A$ abandon his/her argument, or simply modify it as now statistical? Our hypothesis is the later. We should note that once one moves from universally quantified claims to statistical claims, the ways in which an argument is evaluated may change in interesting ways. Suppose, for example, that $B$ argues that many individuals, not just he/she, reject $x$. This may seem to transform an appeal to popularity into a debate about statistical suffi-
} 
$\mathrm{P}$ is popularly believed (or not), therefore $\mathrm{P}$ is true (or not)

...where just because $\mathrm{P}$ is popular/unpopular, $\mathrm{P}$ 's truth/falsity is claimed. This is the "outrageous" inference, for Johnson and Blair. Before examining this inference-type in detail, it is worth noting that, having specified their target, Johnson and Blair walk it back almost immediately:

To argue that a claim is true simply because a certain number of people think it's true is outrageous. However, we doubt that most people who are guilty of the fallacy of popularity are following this line of reasoning. Instead, we expect that they reason (implicitly) as follows: that many people believe something is a good reason for thinking that it is true, or, at least, believing it to be. That's because, so the reasoning goes, there would not be popular acceptance of that belief unless there existed, independently, good reasons for thinking it to be true... the popularity of the belief is some evidence of good reasons for accepting it (Johnson and Blair 2006, p. 177).

Their analysis here can be expressed more clearly in this less blatant form of the argument:

1. There is popular belief that $\mathrm{P}$ (or not-P).

2. When there is popular belief (or not) of some claim, there are likely to be good reasons for that statement's truth (or falsity), therefore

3. $\mathrm{P}$ is true (or not)

This less blatant form shifts the burden of argument onto the second premise. As Johnson and Blair note, it's a premise that, under some circumstances, might be acceptable. If everyone in a community believes that the fish in a nearby lake are contaminated, that's a good reason for one to believe that the fish are contaminated (2006, p. 177). The upshot of this less blatant version is that,

ciency. But note that such a debate, even if it occurs, may not deny the imagined legitimacy of appealing to popularity. Instead, the debate is whether or not there really is popularity in the first place. 
properly contextualized, an appeal to popularity "is not always an irrelevant reason for accepting a proposition” (p. 177).

It is an empirical question as to what people do intend when they advance an appeal to popularity. Johnson and Blair themselves take it that the blatant fallacy of popularity is rare (Johnson and Blair 2006, p. 177). Why should we imagine that it is ever committed, that is, that anyone ever intends the blatant version? Perhaps everyone that appeals to popularity is really appealing to potential reasons that are merely represented by the placeholder 'popularity'. As we say, this is an empirical question, or questions, such as: Does anyone really think that a belief is likely to be true because most people believe it? Is a majority of believers sufficient (or what percentage/ratio)? How rare are such appeals? As interesting as these questions and their actual answers are (and we shall discuss the first two, below), there are good reasons to care about the blatant form argument, no matter how rare it might be in the wild.

In the first place, noting the difference between the blatant and less blatant forms of the argument constitutes (at least part of) an analysis of appeal to popularity. Awareness of the difference between the blatant and less blatant versions can enable us to ask questions about what a speaker intends. If popularity really is just a placeholder for "reasons", then we can point out that it is the reasons not the popularity that matter to argument acceptability, and this may shift discussion towards a rational basis for the argument that is more satisfactory (to most philosophers, at least).

In the second place, having ascertained that an appeal to popularity really is an appeal to reasons, it does not follow that such an appeal is legitimate. By this we mean more than the claim that the reasons might not be sufficient. We might imagine, for example, that a speaker does intend the less blatant argument form but accepts premise 2 baldly as a general principle. This, however, only recapitulates the outrageous inference of the blatant form, in the sense that one accepts the appeal to popularity on the basis of a principle that is only intended to point one toward the real reasons for the popular belief - a placeholder - and not function as a reason 
in itself. ${ }^{3}$ To take it as such is to beg the question - for the less blatant form to collapse into the blatant form, or so it seems.

Thirdly, we want (that is, we the authors want) to distinguish the blatant and less blatant forms because, we shall argue, the blatant form is, under certain conditions, an acceptable inference, independent of more fulsome, less blatant formulations.

\section{Defending the view of the many-the blatant appeal to popularity}

Is an appeal to popularity-a blatant appeal — always a fallacy of popularity? A better question might be: is it ever such? In the quotation at the head of this article, Systma and Livengood remind us of Socrates' disdain for majority opinion - a disdain that continues to the present. A cursory evaluation of contemporary critical thinking texts yields agreement with those authors: ad populum as the fallacy of popularity is often called ${ }^{4}$ is treated as a common falla$\mathrm{cy} ;{ }^{5}$ majority opinion is not a guide to the truth. Though this may

\footnotetext{
${ }^{3}$ When Walton points out that an appeal to popularity may in fact be an instance of appeal to expertise (and hence potentially a good/bad argument of that sort, according to its criteria), or when Freeman argues that some appeals to popularity really are appeals to common sense, they are claiming that popularity is a placeholder for some more content-full set of premises that do the actual argumentative work. Both authors are, in effect, [a] adopting the less blatant version of the appeal to popularity and then [b] re-describing its premise 2 in such a way that it is no longer best understood as an appeal to popularity. Neither author is defending the blatant form of the argument.

${ }^{4}$ We prefer Johnson and Blair's "fallacy of popularity" because it is narrower than many formulations of ad populum. (See, for example, Walton 1982 for a discussion.) This is not an arbitrary decision, as the formulation we focus on, the blatant form, is the most difficult to square with common philosophical opinion about the fallacious nature of appeals to authority.

${ }^{5}$ One interesting exception is Woods, who treats ad populum (and other supposed fallacies) as non-fallacious. Wood's view is that the classic fallacies "the gang of eighteen" as he calls them, are either not mistakes, or not typical mistakes humans make (Woods 2007). While we do not agree with Wood's view of the classic fallacies (but see his 2013), we do think he is right in claiming that the ways in which the classic "fallacies" are usually analyzed may bear little resemblance to the ways their base inferences should be analyzed. This paper exemplifies that view for appeals to popularity. Woods' positive thesis, which locates the
} 
be a correct observation, Sytsma and Livengood are critical of this consensus, and argue that, at least some of the time, majority opinion is a guide to the truth. Since their argument, which we shall develop in somewhat more detail, is formulated with reference to Condorcet's jury theorem, we will start with that.

Stated plainly, Condorcet's jury theorem (CJT) establishes that majority agreement, given the satisfaction of certain conditions, is a reliable indicator of truth. Informally, CJT can be described as follows. What is the probability of a jury (more generally, a set of voters) arriving at a correct binary decision: guilty or innocent (more generally: true or false)? If the probability of each individual member of the jury arriving at a correct binary decision is greater than half (such that each voter is more likely to vote correctly, than incorrectly), then the probability of a correct decision increases as the number of voters increases. Juries are restricted in size, but voting populations may be larger, affording the possibility of high degrees of probability (converging to 1 ) for such cases. Thus, majority opinion is a guide to a correct decision - to truth (or falsity), in the general case. Here is a simple illustration ${ }^{6}$ of CJT, for a "jury" of three individuals:

Assume that voters have a $2 / 3$ chance of getting a binary choice right (.67); $1 / 3$ chance of getting it wrong (.33), where $\mathrm{P}$ means "the probability of..."; A means "A is the right choice"; $\mathrm{A}^{\prime}$ means "A is the wrong choice".

Getting it right

$$
\begin{aligned}
& \mathrm{P}(\mathrm{A})=1-\mathrm{P}\left(\mathrm{A}^{\prime}\right), \text { so } \\
& \mathrm{P}(\mathrm{A})=1-.33=.67
\end{aligned}
$$

Getting it wrong

$$
\begin{aligned}
& \mathrm{P}\left(\mathrm{A}^{\prime}\right)=1-\mathrm{P}(\mathrm{A}), \text { so } \\
& \mathrm{P}\left(\mathrm{A}^{\prime}\right)=1-.67=.33
\end{aligned}
$$

concerns of informal logic within the scope of cognitive science is a welcome approach.

${ }^{6}$ This illustration of CJT, with some modification, comes from a talk by G. Mikkelson (2018). Used with permission from the author. 
Probability all three voters choose right: $.67 \times .67 \times .67=.30$

Probability all three voters choose wrong: $.33 \times .33 \times .33=.04$

Other possible voter distributions can be calculated in similar fashion, by the multiplication of the individual probabilities for each voter in a given possible distribution of voters choosing right or wrong as the case may be (the limit to the number of distributions is set by the logically possible set of distinct distributions, eight in this case). The probability of the group decision being right/wrong sums the probabilities of all possible right decisions/all possible wrong decisions for the group:

\begin{tabular}{|l|l|l|l|l|l|}
\hline Voter 1 & Voter 2 & Voter 3 & $\begin{array}{l}\text { Sum } \\
\text { decision }\end{array}$ & $\begin{array}{l}\text { P(approx.) } \\
\text { of each } \\
\text { possible } \\
\text { distribution }\end{array}$ & $\begin{array}{l}\text { P of group } \\
\text { right deci- } \\
\text { sion }\end{array}$ \\
\hline right & right & right & right & $30 \%$ & \\
\hline right & right & wrong & right & $15 \%$ & \\
\hline right & wrong & right & right & $15 \%$ & $75 \%$ \\
\hline wrong & right & right & right & $\begin{array}{l}15 \% \\
\text { sum }\end{array}$ & $7 \%$ \\
\hline wrong & wrong & wrong & wrong & $4 \%$ & \\
\hline right & wrong & wrong & wrong & $7 \%$ & $7 \%$ \\
\hline wrong & right & wrong & wrong & $7 \%$ & $\begin{array}{l}7 \% \\
\text { sum }=\end{array}$ \\
\hline wrong & wrong & right & wrong & $25 \%$ \\
\hline
\end{tabular}

The probability of the group making the right decision, for this scenario, is greater than the probability of any one individual in the group getting it right. This consequence has led commentators on CJT to point out that there is "wisdom in numbers" and that the probability of a group making correct decisions is greater than that of any individual in the group. ${ }^{7}$

${ }^{7}$ Condorcet's Jury Theorem has an interesting history, having been discovered by the Marquis de Condorcet in the $18^{\text {th }}$ Century, then forgotten until the mid- 
Does CJT establish the blatant appeal to popularity as legitimate? As noted, it depends upon the satisfaction of certain conditions, some of which have already been mentioned. The decision must be binary, a choice between guilty/innocent, true/false. Each voter must have a probability greater than one half, of choosing correctly: this is usually described as an assumption of competence. (If the probability they will choose correctly is less than half, then the probability the choice made will be correct decreases with the number of voters.) Finally, and not mentioned in our description, the voters must vote independently of one another. How likely is it that these three conditions, ${ }^{8}$ binary, competence, and independence are satisfied?

There are theoretical reasons for requiring binary choice. The CJT will not help with preference orders as arise, say, in a 3-person election (Arrow 1950). It is crucial to CJT that choice be "dichotomous... there is only one way of being wrong" (McCannon 2015). This might be construed as nothing more than a commitment to the principle of bivalence, a principle that is widely-perhaps wildlypopular among analytical philosophers. However intuitive this interpretation of "binary" might be, bivalence is essentially a metalogical principle - a rule as to how one is to interpret declarative statements, namely, as true or false, not both, nor neither. For a choice to be binary (or, if one wishes, bivalent and binary) then it must be a clear choice between an option A and an option B (it must, that is, be analogous to a vote for A over B). Bivalent claims which do not present clear choices between an A and a B are likely to be open ended, and in this context that means they may imply preference orderings of the sort Arrow's theorem applies to. Consider this claim: "The Chrysler minivan is the best minivan." Bivalent, yes; binary, no. Though this claim does not explicitly specify a preference ordering, it implies the Chrysler minivan is not just better than a clearly specified option, but the best among some set of options. For a variety of reasons, originally detailed by the econo-

$20^{\text {th }}$. Current statements of the theorem are robust, have withstood many challenges, and stand as a cornerstone in social choice theory. A good discussion of CJT, including its formal specification, can be found in McCannon (2015).

${ }^{8}$ There are other conditions, such as sincerity, but these three have received the most attention as they cannot be significantly relaxed (McCannon 2015) 
mist Kenneth Arrow, preference orders of greater than 2 choices cannot be resolved into the preference for a group. ${ }^{9}$

The assumption of competence turns out to be weak, requiring a bias toward a correct decision of barely more than one half. In initial formulations of CJT, it was assumed that each voter had to be competent-more likely to vote correctly than not-but more recent formulations relax this assumption such that a group's aggregate bias toward a correct decision is sufficient under most conditions (e.g., Grofman, Owen and Feld 1983). One needs, then, assume only that some familiarity with the grounds for a decision, distributed across a population, is sufficient for competence. CJT is, it should be clear, inherently probabilistic. All conclusions derived on its basis are probabilistic, though the probabilities may be high. Thus, we are making a claim to probable truth, not a claim of truth. But this may seem to miss a major point of concern, which is about epistemic competence not the calculation of probabilities: who, exactly, is competent to make assessments about what's true; surely not anyone/everyone? Consider the following claim which is both bivalent and binary:

Intelligent alien civilizations exist in the universe.

Bivalence commits us to the view that this claim is either true or false. It is binary because assent to this claim is essentially a vote for existence, against non-existence. If we assume competence and independence, then we should assent to an appropriate majority opinion. But this is bound to be an unsatisfactory result, for many. If no one knows if there are such civilizations, how can the majori-

\footnotetext{
${ }^{9}$ Condorcet recognized this problem as well. If there are three or more candidates in an election, preferences may "cycle" (i.e. may not be transitive), leading to no clear "Condorcet winner" (McCannon 2015). Arrow's work on voting rules ("social choice functions") begins with the assumption that any successful rule for establishing the group preference must be transitive. With the addition of four further assumptions that are widely regarded as reasonable, Arrow concludes there can be no successful rule. For this reason, Arrow's theorem is often characterized as "Arrow's impossibility theorem." (For a discussion of Arrow's theorem and its significance see Penn 2015).
} 
ty decide it to be so $?^{10}$ For CJT to be applicable we need to have confidence that a population is more likely to make a correct decision. But we do not know the truth and, because that is so, we may have no idea as to what factors are relevant for competence. Thus, CJT is not a guide to truth because competence cannot be assumed without begging the question.

In their brief discussion of CJT, Sytsma and Livengood respond to this sort of argument by noting that it amounts to a general skepticism about competence. They hold that, while specific criticism may be warranted, the burden of proof is on the critic to articulate specific features that make a judgement problematical. We are sympathetic to this line of argument on the grounds that a general skepticism is always available and hence of little practical significance and, though Sytsma and Livengood are mainly concerned with issues in experimental philosophy, ${ }^{11}$ their response can be refined for the more general case. Consider the following three maxims, when it comes to competence decisions:

1. Assume aggregate competence at tracking binary truth claims is less than .5.

2. Assume that aggregate competence at tracking binary truthclaims is greater than .5 .

3. Assume the degree of competence depends on the binary truth claim being tracked

10 A Glocalities survey (https://www.glocalities.com/reports/majority-ofhumanity-say-we-are-not-alone-in-the-universe; reported by Lampert 2017) found that $61 \%$ of earthlings (sample size 26,492 from 24 countries) answered "yes" to "Do you believe in the existence of intelligent alien civilizations in the universe." If this is not precisely a binary claim, it can be converted to such.

${ }^{11}$ Sytsma and Livengood (2016) wish to make an argument for the legitimacy of experimental intuitional philosophy and are concerned to defend the idea that such experiments can track the actual philosophical intuitions of individuals (be they laypersons or philosophers). As such, they make a case that it is prima facie reasonable to believe, for a properly constructed binary choice, that individuals have a better than half chance of choosing the option that really does track their intuition. We should assume, in other words, that such individuals are competent relative to the sort of choices posed by experimental intuitional philosophers, all things being equal. It is not our purpose to comment on experimental philosophy. We believe, however, that the prima facie case is stronger for intuitions than it is for the general binary case when it comes to competence. 
Our view is that we should reject 1 as an unwarranted general skepticism about competence, and adopt a combination of 2 and 3. We advocate, that is, a view similar to the one that, as Kant pointed out, almost everyone must take when it comes to lying: assume people are telling the truth unless you have reason to believe otherwise. Our maxim for competence: Assume aggregate competence at tracking binary truth claims is greater than .5 , unless the nature of the claim suggests otherwise. This maxim allows us to deal with the case of intelligent alien life in the following way: since it is not clear what the evidence is for this claim is at all, we have no reason to believe competence is satisfied.

Finally, there is the independence condition. The idea here is that, conditional upon their understanding of the evidence, individual voters make their decisions independent of others. If they do not do so, large populations will collapse into smaller populations, with a decrease in the probability of correct decision. We know this often happens. To cite a recent idea: there are internet filter bubbles (Pariser 2011) which may cause, say, a former USA Secretary of State to be viewed by those in a filter bubble as a child molester (with the attendant electoral risk). As problematical as this may be, it is less of an issue for large populations (than, say, for juries). The influence of "opinion leaders" may reduce the number of independent voters without eliminating the power of popularity as a truth tracker (e.g., Estlund 1994). We shall have more to say about independence, as well as binary and competence, in Section 3.

\section{Appeals to popularity revisited}

We start this final section with our prescriptive conclusion (PC), stated as clearly as possible, and work towards its defense:

PC: The idea that appeals to popularity commit a fallacy of popularity should be dropped in critical thinking discourse.

In Section 1 we isolated the nature of the supposed fallacy of popularity as involving this sort of inference: 
"P is popularly believed, so $\mathrm{P}$ is true" or "P is not popularly believed, so P is false."

We now take it that this sort of inference should not be treated as fallacious because, for a large class of cases, this type of inference is legitimate. The descriptions of the fallacies are intended to be "heuristic" in providing generally reliable rules that are nonetheless defeasible under certain conditions. They do not specify strict decision procedures. The complexity of reasoning in natural language pretty much requires this to be so, for many if not all of the classic fallacies, and almost every critical thinking text we have examined is careful to discuss examples that look to be instances of a particular fallacy but are not. Indeed, many of the discussions of popularity we have mentioned in this article deal with such cases (e.g., Walton 1982; Freeman 1995; Govier 2005; Johnson and Blair 2006; Epstein 2011). Defeasibility does not in itself vitiate an interest in the fallacies (in our view): uncertainty as to the application of a general rule comes with the difficulties of interpreting natural language and speaker's intent - comes, that is to say, with the territory. Our objection to the fallacy of popularity is not that its rule"reject the blatant form of appeal to popularity"-has exceptions. Rather, it is that the rule is not itself one that should be adopted in the first place. It really is a fallacy to make a generalization that is hasty; it really is a fallacy to beg the question. It is not, in the first place, a fallacy to appeal to the popularity of a belief as evidence for its truth. That is the upshot of CJT.

The idea that inferences from popularity are "outrageous" (as Johnson and Blair put it) may produce an unwarranted bias that, in many cases, conceals other problems with an argument. Consider the examples discussed by Johnson and Blair (2006, p. 179):

I. Chrysler minivan - the best-selling van in America.

II. More than 250,000 hairdressers the world over believe in what L'Oréal Hair Coloring can do for you.

For the authors, both of these advertisements conflate popular belief with truth and are thus instances of a fallacy of popularity. (p. 180) With respect to I, suppose we count a minivan purchase as a 
vote for the truth of this claim: "The Chrysler minivan is the best van (in America)." We take the explicit argument to be something like this:

P1. The Chrysler minivan is the best-selling van in the USA.

$\mathrm{P} 2$. The best-selling van in the USA is the best van in the USA.

Sub C (P3). The Chrysler minivan is the best van in the USA.

P4. When shopping for a van, buy the best van in the USA.

C. You (anyone) should buy the Chrysler minivan

It may seem, in defending appeals to popularity, we must take the view that the inference to Sub C (P3) in this argument is acceptable - that the premises do provide evidence for the conclusion, and that we must try to defend that position by arguing it is nothing but epistemic arrogance that concludes the many are incapable of making a correct judgement. While we are sympathetic to this line of thought in a general way, it does not apply to this case. This claim is not binary. It implies a preference ranking, specifically, the claim that the Chrysler minivan is better than other minivans in America, of which there are many: choice is "polychotomous." Thus, the real problem with this claim, and the argument we have generated from it, has more to do with problems with the word "best" than with an appeal to popularity. The term "best" implies a ranking, or series of rankings, and no information as to that ranking other than sales information is available. Interpreting this argument as nothing more than a fallacious appeal to popularity conceals its real problem.

As for II, it does not seem to be an appeal to popularity (and it is not clear how to standardize the implicit argument, though its main conclusion is the prescriptive "Buy L'Oréal."). It is better construed as an appeal to expertise, where the claim is that hairdressers are "experts" (N.B. Walton 1982). As such, at best, it is an appeal to expertise, and possibly we will reject it because we think that hairdressers are not experts, or because we think they are experts but are biased due to incentives from a corporation (in the same way we think some scientists are biased by their funding sources). In this later case, the inference may fail because the individuals that compose the relevant group are not independent. Even if we were to construe it as an appeal to popularity (along the lines of "Most 
climate scientists believe significant climate change is caused by human activity") there is, once again, a lack of information: does an appropriate majority of hairdressers "believe in" L'Oréal? What do they think about other products? What is the binary choice involved?

It can be argued that one can parse examples like these ever so finely in order to make a favoured case, when, in fact, there are often multiple problems with a piece of reasoning. This criticism is fair and is consistent with our view that fallacy classification is in general difficult. Yet we think it is beside the point. While CJT does not guarantee that an appeal to popularity is an acceptable inference, we should pause when it comes to attributing fallacy to such appeals for two reasons: one, we have a prima facie reason for believing that binary choices are appropriate candidates for a legitimate appeal to popularity and, two (even more importantly in our opinion), the conditions on CJT provide us with analytical tools that permit more powerful critiques of arguments that make, or appear to make, appeals to popularity. The three conditions: binary, competence, and independence represent legitimate criteria informal logic may use to evaluate appeals to popularity.

Issues as to competence are real, but we should not, as we argued in Section 2, adopt a general skepticism about competence, assuming that populations are unlikely to have a bias toward the truth. Competence, on CJT, requires that a truth-tracking bias is distributed across a population that includes the expert, the ignorant, and those in between; it requires that we (philosophers, say) believe choices are made conditional on an individual's understanding of the evidence, where the truth is out there, and there is sufficient information to support a bias toward it. Recall, as well, that the CJT is probabilistic. At the very least we should take appropriate majority judgements to be evidence for the truth of a claim, rather than clear examples of blatantly fallacious inference. That said, there are cases where competence really is an issue. Our claim about intelligent alien civilizations would seem to be an example of this. But note this is a specific example, and it is the features of this example that should make us skeptical as to competence rather than a general skepticism about competence. One commonly cited expert way of evaluating the intelligent alien civi- 
lizations claim, the "Drake equation", ${ }^{12}$ involves seven variables, of which we may be able to approximate the values of only two. The point, here, is not that we should devolve our decision making to experts, but that there is no ground for any claim to competence. In such cases one ought to conclude that the competence criterion for $\mathrm{CJT}$ is not satisfied, and that an appropriate majority opinion is not the basis for accepting the claim as probably true, or even as evidence for its truth.

The third condition for CJT, independence, is another useful tool when it comes to evaluating appeals to popularity. We have pointed out that a large population may collapse into a much smaller set of functional individuals (as opposed to numerical individuals) due to the effect of "opinion leaders." The effect is to make some subset of individuals count as one: they are not making their judgements conditional upon their understanding of the evidence, but conditional upon the beliefs of others. This is another real concern. Internet "influencer" is actually a job title. ${ }^{13}$ Internet filter bubbles abound (Pariser 2011). Even some respectable versions of cultural evolutionary theory propose that following the behavior of highstatus individuals is a legitimate cultural evolutionary strategy. (Henrich and Gil-White 2001) Our purpose is not to deny the relevance of independence, but to promote it as a criterion for the evaluation of appeals to popularity. While we have already pointed out that the role of opinion leaders does not vitiate CJT in principle, the degree to which a decision is based on the beliefs of opinion leaders is an issue. A main concern is whether all opinion leaders are biased in the same direction, and away from truth. If opinion leaders are equally distributed in terms of their biases, they may essentially cancel one-another out. But, of course, they may not. Our point, we should say, is not to require the introduction of detailed, empirically grounded probability calculations necessary for CJT into informal logic. The value of fallacy identification is that it is

\footnotetext{
${ }^{12}$ A discussion of the Drake equation by M. Williams can be found at Universe Today: space and astronomy news:

https://www.universetoday.com/39966/drake-equation-1/

${ }^{13}$ See, for example, this list from Forbes:

http://www.forbes.com/top-influencers/\#59d1261f72dd
} 
heuristic. Making the claim that one needs to determine [a] the number of opinion leaders [b] the scope of their influence, and [c] restate our probabilities for the re-construed population's decisions takes us far beyond the quick-and-dirty evaluations we give when assigning a fallacy-name to a piece of reasoning. But we often do make quick-and-dirty assignments, even in cases where probabilities (say) are relevant. It may, for example, be difficult to tell exactly when an argument involves a hasty generalization, yet there are cases where, in the absence of detailed probability calculations we could generate with the methods of the social sciences, we do make such an assignment: when a sample size is obviously insufficient. We take it that the same approach should be applied here: it is valuable to identify the opinion leaders and their biases, and to suggest they problematize an appeal to popularity, when that case seems overwhelming/underwhelming. President Trump's claims to the effect that "everybody knows..." 14 would seem to be a case in point if the "everybody" is constituted by biased news sources, and their influence on his "base". Note that this critique of Trump's appeals to popularity is not an appeal to a general skepticism about independence (namely, that opinion leaders are assumed to be decisive, and that the onus is on one to show they are not), but to information that is widely available in North American culture.

It should be clear by now that we are not defending all the inferences that are described in the literature (and of course elsewhere) as appeals to popularity. In many cases they will fail, but for reasons either unrelated or only partially related to popularity itself. So, for example, in Johnson and Blair's minivan example, we take it that there is some way in which the popularity of that vehicle, expressed in terms of its sales numbers, does and should matter to people desirous of a minivan. But the fact that minivan choice is polychotomous muddies the waters as to what exactly that is, a common problem with many appeals to popularity. Consider a different example from Govier: "an argument that square dancing isn't any good because nobody does it anymore would be a falla-

\footnotetext{
${ }^{14}$ The transcript of an interview with the New York Times provides a number of examples:

https://www.nytimes.com/2017/12/28/us/politics/trump-interview-excerpts.html
} 
cious appeal to unpopularity" (Govier 2005, p.188). The power of Govier's claim resides in the juxtaposition of two ideas. The first is the idea of its unpopularity; the second is the idea of value. Surely one can see that its goodness does not depend on whether or not it is popular! But introducing the notion of "good" into the discussion of this fallacy, we open up a range of possibilities as to what constitutes the goodness of square-dancing (or its lack thereof). It is easy for one to think that there could be reasons for its goodness: historical, cultural, for the sake of exercise or aesthetics - and that these reasons could be reasons for some people, perhaps ourselves, to think it is "good". That is fair enough. But the CJT does not require that everyone assent to the non-goodness of square-dancing, any more than it requires everyone to find an individual guilty, or for everyone to believe the truth of $\mathrm{P}$, where the probability of a correct choice is $>.5$, distributed across the population. That said, we believe that the inference from fact to value is the main problem here. Here is Govier's argument, baldly stated:

P1. Nobody (very few people) square-dance anymore.

C. Square dancing is not good.

This fact-to-value inference is problematical in the way that all fact-to-value inferences are problematical, and the waters are muddied. Consider, then, a related inference more in line with the blatant form of the appeal to popularity, again baldly stated:

P1. Very few people believe that square dancing is good.

C. It is true that square-dancing is not good.

While this version of the argument is within the realm of value, the issues mentioned above concerning the ways in which things may be good arise. It is impossible to know what the truth conditions are for the premise in this argument, as stated. If "good" is viewed in comparative terms (as we think it should be ${ }^{15}$ ) then the issues concerning preference rankings and their comparisons arise. On our view, this argument fails not because of the appeal to popularity,

15 The idea of "intrinsic goodness" seems out of place in this case. 
but because the implicit claim "Square dancing is not good" is not binary. ${ }^{16}$

So: we are not advocating the blanket acceptance of the large class of arguments that informal logic has named (though there is various nomenclature) "fallacious appeal to popularity." We do claim that an appeal to popularity is not, prima facie, an error in reasoning. Many examples in the denominated class fail as arguments, but often this is because of reasons distinct from popularity - reasons that are often masked by classifying an appeal to popularity as fallacious. We have pointed out that the conditions for the successful application of CJT-binary, competence, and independence-provide legitimate and useful criteria for the evaluation of appeals to popularity, and we propose they be adopted in a general way within informal logic. ${ }^{17}$

\section{References}

Arrow, K. 1950. A difficulty in the concept of social welfare. Journal of Political Economy 58 (4): 328-346.

Epstein, R. L. 2011. A pocket guide to critical thinking (4 ${ }^{\text {th }}$ Edition). Advanced Reasoning Forum.

Estlund, D. M. 1994. Opinion leaders, independence, and Condorcet's Jury Theorem. Theory and Decision 36: 131.

Forbes Magazine. 2018. Top influencers 2017. URL accessed 05/07/2018: http://www.forbes.com/top-influencers/\#59d1261f72dd

\footnotetext{
${ }^{16}$ Christian Stevens, and one anonymous referee for an earlier draft of this paper, have pointed out that very few claims one finds, in the wild, are going to be binary in the requisite sense. This, we think, is true. We note that there are two models for the framing of proper binary claims. The first is, of course, a two candidate vote and the second is the social sciences. Questionnaire design faces up to at least some of the problems identified in this paper-polychotomy, in particular.

${ }^{17}$ I would like to thank Christian Stevens and Mark McCullagh for comments on an earlier draft. Thanks also the anonymous referees for their helpful criticism.
} 
Freeman. J. B. 1995. The appeal to popularity and presumption by common knowledge. In Fallacies: Classical and contemporary readings, eds. H. Hansen and R.C. Pinto, 265-273. University Park, Pennsylvania: The Pennsylvania State University Press.

Govier, T. 2005. A practical study of argument, $6^{\text {th }}$ edition. Thompson Wadsworth.

Heckelmann, J. C. and N. R. Miller, eds. 2015. Handbook of social choice and voting. Edward Elgar.

Grofman, B., G. Owen, and S. Feld. 1983. Thirteen theorems in search of the truth. Theory and Decision 15: 261-278.

Henrich, J., and F. Gil-White. 2001. The evolution of prestige: Freely conferred deference as a mechanism for enhancing the benefits of cultural transmission. Evolution and Human Behavior 22(3), 165-196.

Johnson, R. H. and A. Blair. 2006. Logical self-defence. IDEA.

Lampert M. 2017. Majority of humanity say we are not alone in the universe. Geolocalities. URL accessed 05/07/2018:

https://www.glocalities.com/reports/majority-of-humanity-say-we-arenot-alone-in-the-universe

McCannon, B. C. 2015. Condorcet jury theorems. In Handbook of social choice and voting, eds. J. C. Heckelman and N.R. Miller. Edward Elgar.

Mikkelson, G. 2018. The Condorcet jury theorem: More than meets the eye. Invited talk. University of Montreal, 20 Feb. 2018.

Pariser, E. 2011. The filter bubble: What the internet is hiding from you. Penguin.

Penn, E. M. 2015. Arrow's theorem and its descendants. In Handbook of social choice and voting, eds. J. C. Heckelman and N. R. Miller, 237262, Edward Elgar.

Sytsma, J., and J. Livengood. 2016. The theory and practice of experimental philosophy. Broadview. 
The New York Times. 2017. Excerpts from Trump's interview with The Times. URL accessed 05/07/2018:

https://www.nytimes.com/2017/12/28/us/politics/trump-interviewexcerpts.html

Walton, D. N. 1980. Why is the ad populum a fallacy? Philosophy and Rhetoric 13(4): 264-278.

Williams, M. 2017. What is the Drake equation? Universe Today: space and astronomy news. URL accessed 05/07/2018: https://www.universetoday.com/39966/drake-equation-1/

Woods, J. 2013. Errors of reasoning. College Publications.

Woods J. 2007. The concept of fallacy is empty: A resource-bound approach to error. In Model-based reasoning in science, technology, and medicine, eds. L. Magnani and P. Li, 69-90. Springer. 